\title{
Determinants of Historic and Cultural Landmark Designation: Why We Preserve What We Preserve
}

\author{
Douglas S. Noonan \\ Associate Professor \\ School of Public Policy \\ Georgia Institute of Technology \\ Atlanta, GA 30332-0345
}

tel: $404-385-4257$

fax: 404-835-0504

email: doug.noonan@gatech.edu

\section{Douglas Krupka}

University of Michigan and IZA

Final version published as:

Noonan, D. S., \& Krupka, D. J. (2010). Determinants of historic and cultural landmark designation: why we preserve what we preserve. Journal of Cultural Economics, 34(1), 1-26. doi:10.1007/s10824-009-9110-6

\begin{abstract}
:
There is much interest among cultural economists in assessing the effects of heritage preservation policies. There has been less interest in modeling the policy choices made in historic and cultural landmark preservation. This paper builds an economic model of a landmark designation that highlights the tensions between the interests of owners of cultural amenities and the interests of the neighboring community. We perform empirical tests by estimating a discrete choice model for landmark preservation using data from Chicago, combining the Chicago Historical Resources Survey of over 17,000 historic structures with property sales, Census, and other geographic data. The data allow us to explain why some properties were designated landmarks (or landmark districts) and others were not. The results identify the influence of property characteristics, local socio-economic factors, and measures of historic and cultural quality. The results emphasize the political economy of implementing preservation policies.
\end{abstract}

Keywords: Heritage preservation policy, landmark designation JEL code: Z1, R52, D78

This document contains demographic data from Geolytics, Inc East Brunswick, NJ. 


\section{Introduction}

Since the 1960s, historical preservation policies have been used to protect local cultural landmarks, as well as to promote local development. Landmark designation by local governments may have various effects on the value of historical and cultural properties and their neighbors. There has been some interest by academics and policy advocates, for instance, in assessing the effects of landmark designation on property values, with mixed results. There has been less interest in modeling the designation process itself; but without understanding how designation occurs, making causal inferences about historic and cultural preservation policies will be problematic. This paper develops a theoretical model of landmark designation and explores empirical determinants of designation using a combination of several rich datasets for buildings in Chicago.

The theoretical model highlights several key aspects of historic landmark preservation policies. The model highlights the costs and benefits of designation, the choice among alternative policy instruments, and how political economic considerations affect the preservation decisions of program administrators. We develop a discrete choice model for landmark designation which identifies the determinants of designation. Among the determinants tested are a rich array of property characteristics, local economic and demographic characteristics, and other geographic variables for the property. Such quantitative methods highlight certain types of determinants while leaving the more colorful political process through which designations are proposed, considered, and finalized to more qualitative analyses. The model is applied to data for Chicago, combining the Chicago Historical Resources Survey of over 17,000 historic and 
architecturally noteworthy structures in the city with Multiple Listing Service sales data for over 70,000 attached-home properties in the city during the 1990s. The data allow us to explain why some properties were designated landmarks (or landmark districts) and others were not. This enables us to better understand the forces that lead to historic preservation and local economic development, as well as understand the biases in causal inferences about the price effects of historic designation.

The rest of the paper is organized as follows. Section II discusses the relevant literatures and policy background. A simple, general theory of the regulation decision is developed in the third section, while a fourth section relates the theory to the empirical analysis and describes the data we use. Section V presents the results of the empirical analysis, focusing on the policy choice of the historical regulator and the robustness of these results to various changes in the model or sample. A final section concludes.

\section{Literature review and policy background}

Heritage preservation efforts take many forms. Sometimes the efforts include public or private ownership and a choice to maintain and preserve the resource. More indirect efforts include providing incentives to others for their preservation activities. This might include sponsorship or underwriting of an activity (e.g., performing some traditional rite, maintaining an aging structure) by private or public funds. Schuster (2002) calls attention to a suite of historic preservation policy tools that he refers to as list-based policies. These include listing, registering, scheduling, and other forms of designations in countless national and local heritage preservation lists.

Among Schuster's many interesting observations about list-based policies, a few merit emphasis here. First, lists can serve their preservation ends by many means in 
various contexts. This includes drawing attention to resources, certification, and enabling eligibility for other policy interventions. This latter set of implications of listing can involve positive or negative incentives (sometimes automatic, sometimes contingent on a competitive application), different regulatory treatment, or other procedural considerations -the origins and implementation of which are often de-coupled from the agency or policy process that makes the list in the first place. Second, these lists of heritage resources are large and growing worldwide. In his 2002 paper, Schuster gives examples from France (with 15,000 listed monuments and 31,000 registered monuments), the United Kingdom (with 528,383 listed buildings and over 10,000 conservation areas), United States (with over 1 million historic buildings and 2,300 National Historic Landmarks), and UNESCO’s World Heritage List (with 721 sites in 2001 and now boasts 851 properties). There is much concern about the designation process itself, the criteria for listing, and the possibility of congestion or crowding-out on the list. Understanding the impacts of historic designation policies presents an important challenge given the scope of these lists and numerous governing authorities (e.g., the U.S. alone hosts over 2,000 local historic district commissions).

Scholarly research on historic designations remains fairly limited, although the collection of property price studies has grown. Using the policy's effects on property prices as a prominent indicator of value, several studies have explored the effects of historical quality and local and national historic designation programs. Readers are pointed to an extensive literature review by Mason (2005) and a somewhat dated Listokin and Lahr (1997) report. More recently, studies by Coulson and Leichenko (2004), Coulson and Lahr (2005), Cyrenne et al. (2006), and Ahlfeldt and Maennig (2009) add to 
this growing literature. Recently, Noonan (2007) provides a study of Chicago’s landmarks program, the focus of this research. The broader literature on the economics of historic preservation features widely varying research quality coupled with a fairly narrow focus on price effects.

Surprisingly, perhaps, little or no attention has been paid to the "supply effects” or impact of these policies on actual conservation or preservation. The attention paid to “own-price” effects of designation has struggled to resolve or even address important issues of measurement (e.g., use of appraisal data, use of neighborhood aggregates) and identification (e.g., is designation exogenous, is preexisting historical quality captured). The academic literature recognizes some of these problems and, especially, the likely heterogeneity across jurisdictions. While discussions of historic designation policies often reference asymmetric information and the importance of “certification” (e.g., Schuster 2002), a theoretical model has yet to be applied and empirical evidence of this effect remains elusive. Moreover, analysts have suggested that historic preservation may benefit neighborhoods by both catalyzing revitalization of neighboring areas (e.g., Coulson and Leichenko 2001; Listokin, Listokin, and Lahr 1998) and stabilizing neighborhoods thus reducing investment risks. Little direct evidence of these effects has been offered, although Noonan (2007) does show in his repeat-sales data that housing units in landmark buildings are actually more likely to be sold multiple times in the 1990s than comparable units.

To date, however, very little has been said about the determinants of designation in the first instance - and even less has been done to empirically describe why we preserve what is preserved. Accordingly, efforts to measure or assess causal impacts of 
these heritage preservation policies remain unconvincing. This paper seeks to remedy this oversight.

\section{Theoretical Model}

This section presents an "as if” model of the designation choice which abstracts away from many of the details of the actual designation process. Such a model highlights some of the important factors in designating properties. We imagine a historic preservation regulator maximizing his administrative utility function with respect to the restrictiveness of his preservation interventions, $r$, which we model as positive and continuous. ${ }^{1}$ The regulator has direct preferences over $r$ and the utilities of the property owner $(P)$ and of other affected stakeholders or neighbors $(N)$. Thus, the administrator will choose the restrictiveness of his intervention into the property market (his preservation policy) in order to maximize:

$$
u(r ; z)=U(P(r ; z), N(r ; z), r ; z),
$$

where $U_{N}, U_{P}>0$ and $U_{r}<0$. The regulator's utility is rising in the welfare of the (regulated) property owner and in the welfare of the neighbors. This is the case because he cares about high property values or because residents apply political and administrative pressure on the administrator to increase their own utility. The administrator balances the property owners and neighbors’ opposing interests in restrictiveness. Property owners prefer to have fewer restrictions $\left(P_{r}<0\right)$ in order to preserve the option of redevelopment. Neighbors favor more restrictions $\left(N_{r}>0\right)$,

\footnotetext{
${ }^{1}$ Although preservation of buildings or other structures is the primary focus of this paper, the model can be readily extended to preservation of other heritage resources, such as artwork or cultural landscapes. The core idea - that a regulator balances interests of the owners (who enjoy options to transform or dispose of the resource) and some external constituency who receives a positive externality from that resource - holds across a variety of cultural applications.
} 
assuming those restrictions do not restrict their own options. Neighbors are expected to value restrictions on their neighbors because this reduces the risk of attractive properties being redeveloped in undesirable ways. The direct preferences over the restrictiveness arise from administrative costs of the program such as the costs of monitoring and enforcing compliance. The first-order direct and indirect preferences over the exogenous factors $^{2} z$ will not be important to the model because they are not choice variables for the administrator. The role of the second-order effects will be important below.

The administrator optimizes on a property-by-property basis by setting the marginal utility of restrictiveness to zero:

$$
\text { (2) } \quad F(r, z)=U_{P} P_{r}+U_{N} N_{r}+U_{r}=0 \text {. }
$$

For interior solutions, equation 2 holds at the optimum and thus implicitly defines $r^{*}$ (the optimal restrictiveness) as a function of $z$. We also assume that the second-order condition (that $F_{r}<0$ ) is satisfied so that equation 2 implicitly defines $r^{*}(z)$ as the utilitymaximizing level of restrictiveness. Using the implicit function rule we can derive the partial effects of any of these exogenous characteristics on the optimal level of restriction, $r^{*}:$

$$
\text { (3) } \frac{\partial r^{*}}{\partial z}=-\left(U_{P} P_{r z}+U_{N} N_{r z}+U_{r z}\right) / D
$$

where $D=F_{r}=U_{P} P_{r r}+U_{N} N_{r r}+U_{r r}<0$ is implied by the assumption that the secondorder condition is satisfied. ${ }^{3}$

\footnotetext{
${ }^{2}$ These exogenous factors will include characteristics of individual properties, owners, or neighborhoods and will be discussed below. The direct and indirect preferences will vary depending on which exogenous factor is considered.

${ }^{3}$ A sufficient condition for this condition to hold are that administrative costs increase more-than-linearly, that the added benefit to neighbors is decreasing in restrictiveness, and that the costs imposed on property owners by restrictions increases about linearly.
} 
Equation 3 helps us understand how independent variation in a host of exogenous neighborhood or property characteristics will affect the optimal level of restrictiveness. In general, such a factor will increase the level of restrictiveness whenever $U_{P} P_{r z}+U_{N} N_{r z}+U_{r z}>0$, which means that it increases the marginal utility of restrictiveness. The term is basically the sum of the effect of $z$ on the marginal utilities of each stakeholder, weighted by the administrator's weight of each stakeholder's utility. To flesh out this condition, we examine some examples of such variables.

Some characteristics of the property affect only the property owners. Such a characteristic might be the value of a property after potential redevelopment. This increases the owner's utility by increasing the value of the property, but should not affect the neighbors. Owners of structures with more redevelopment-related option value will likely have their utility more adversely affected by additional restrictions $\left(U_{P} P_{r z}<0\right)$, while this factor will likely have little effect on the marginal utility of restrictions to the administrator. Thus, the model predicts that factors making potential redevelopment more profitable will decrease the optimal level of restrictions.

Some factors will affect neighbors but not property owners. One such element of $z$ is the negative externalities that would be created if the structure was redeveloped. For instance, if the likely post-redevelopment use of a historic apartment building is a gas station, neighbors will likely value restrictions even more than if the post-redevelopment use is a library or housing. If $z$ is "negative externality associated with redevelopment," $U_{N} N_{r z}>0$, while the other cross-partials will be near zero. Thus, the model predicts that restrictions will increase when the future use of properties will bring more negative externalities. 
The historic nature of the property might both decrease the property owner's utility (outdated structural characteristics, $P_{z}<0$ ) but increase neighbors' utility (rare architectural style, $N_{z}>0$ ). Higher restrictions will tend to make living in a historic property worse ( $P_{r z}<0$, because modifications will be more difficult), but also make its external effect on neighbors more positive $\left(N_{r z} \geq 0\right.$, because reduced uncertainty about the persistence of the positive externalities will benefit risk-averse neighbors). The effect on the costs of regulating will be indeterminate because there is nothing inherent about the historic nature that makes the restrictions harder to administer $\left(U_{r z} \approx 0\right)$. From this, the effect of historical quality on protection or preservation is ambiguous. Neighbors might want more restrictions for historic properties, but owners will be more resistant to these restrictions.

Factors other than the property's own historic qualities might make the difference. For a given level of historic value, the preservation of a property in a more historic neighborhood (with many historic properties) might not add very much to neighbors' utility (i.e., $N_{z}$ and $N_{r z}$ will be smaller in more historic neighborhoods), and less regulation will be expected. If the historic property stands out, say, because it is old compared to the rest of the neighborhood, the opposite holds, and regulation might be more stringent. Similarly, for a given amount of historic significance, a more culturally significant structure will have higher optimal restrictions. Higher incomes might increase people's valuation of flows of historic externalities or increase their ability to pressure the regulator (increase $U_{N} N_{r z}$ ).

Two common features of historic preservation policy are that regulation is limited to a few discrete choices, and that protected properties can be bundled together into 
landmark districts. Our model allows for such group designations, but this is a detail away from which we have abstracted considerably. If an administrator can only make group designation decisions, the optimization problem above is subtly altered. Landmark districts offer administrators another choice in the policy instrument with which they approach the preservation decision. For group or district designations, the neighbors and the property owners are groups which substantially overlap, suggesting that the effects of income and other demographic factors on the optimal restrictiveness could differ markedly from individual property regulations. Similarly, the effect of the nearness of additional historic properties in the vicinity (which lowered the level of individual restrictions) might increase the level of group restrictions since imposing group restrictions might have lower marginal costs per unit to the administrator. Because the determinants of group designation and individual designation can differ so markedly, the optimal level of restrictions will also differ depending on the type of designation. Thus, for a given structure, there will be one optimal level of restrictions for the case of individual building designations, $r_{b}{ }^{*}(z)$, and a different level of restrictiveness for district designations, $r_{d}^{*}(z)$.

Our model adjusts readily to the mostly discrete nature of preservation policy. In the empirical section to follow, the continuous $r^{*}$ terms from the model become latent variables in logit regressions, so that designation will occur whenever $r^{*}$ exceeds some cut-off value. Faced with three regulation possibilities (leave the property alone, designate it as part of a district, or designate it as an individual building), the administrator will choose the one that yields the highest utility. The two types of designations also confer eligibility for different incentive programs (such property or 
income tax reductions, zoning variances and technical assistance). Thus, our multinomial logit analysis will take the district/individual distinction as the primary discrete choice faced by administrators.

\section{Data and empirical model}

\subsection{Empirical model}

In the theoretical model above, the utility the administrator receives from regulating any structure, $i$, according to the optimal regulation for policy instrument $c$ is given by:

(4) $u_{i c}=U\left(r_{c}^{*}\left(z_{i}\right)\right)+\varepsilon_{i c}$,

where $\varepsilon_{i c}$ is a random error term following a type-I extreme value distribution and $c$ can be either no regulation $(n)$, district designation $(d)$ or building designation $(b)$. For our statistical analysis, we assume that

$$
U\left(r_{c}^{*}\left(z_{i}\right)\right)=\beta_{0 c}+\beta_{z c} z_{i}+\varepsilon_{i c} .
$$

If the administrator always chooses the option yielding the highest utility, the probability that he chooses any given preservation policy, $p_{i}$ for a given structure is given by:

(6) $\quad \operatorname{Pr}\left(p_{i}=c\right)=\frac{e^{\beta_{0 c}+\beta_{z c} z_{i}+\varepsilon_{i c}}}{1+\sum_{c} e^{\beta_{0 c}+\beta_{z c} z_{i}+\varepsilon_{i c}}}$

for $c=d, b{ }^{4}$ We estimate these empirical equations via maximum likelihood.

We also perform an analysis of the district designation decisions using standard logistic regressions. There:

\footnotetext{
${ }^{4}$ For policy instrument $c=n$, or no regulation, the probability of being unregulated is set to be equal to equation (6) with the numerator replaced with 1.
} 


$$
\text { (7) } \begin{aligned}
\operatorname{Pr}(c=d \mid z) & =\operatorname{Pr}\left(r_{d} *(z)>0 \mid z\right) \\
= & \operatorname{Pr}\left(\beta_{0}+\beta_{z} z+\varepsilon_{2}>0 \mid z\right)
\end{aligned}
$$

These models are important in terms of checking the robustness of our results, and interesting in their own right. Because of the rarity of individual designations, we are not able to control for large amounts of structural and neighbor characteristics in our multinomial logit analysis. Thus, we assess the robustness of the coefficients in the district-only models, and discuss them in light of the results from the multinomial logit models.

\subsection{Data}

The empirical analysis combines many data sources. The City of Chicago’s Landmarks Division in its Department of Planning and Development provides information on the landmarks (City of Chicago 2004). Information such as the addresses, dates of construction and designation, architect and architectural style, and historic themes are available for the 217 individual landmarks and 43 historic districts (comprising over 4,500 properties) in the city. These data provide us with the dependent variables of our empirical analysis, which is designation during the 1990’s.

Combined with the official landmarks data is the Chicago Historical Resources Survey (CHRS). Starting in 1983, historians from the Landmarks Commission inventoried the half million structures in Chicago’s city limits (Commission on Chicago Landmarks 1996). Commission on Chicago Landmarks (1996) describes the methodology in greater detail. Ultimately, the fieldwork obtained detailed information from a final sample of 17,366 historically and/or culturally significant properties. The CHRS data contains information on addresses, architects, significance and maintenance, and construction dates (http://www.cityofchicago.org/Landmarks/CHRS.html). The 
analysis also uses a variety of other geographic data for the city including Chicago's community areas and Census TIGER files. To link properties to their block-group level Census variables, the Geolytics ${ }^{\mathrm{TM}}$ dataset is employed to produce boundary-constant neighborhood demographics for 1980-2000.

To examine which properties are more likely to be designated as landmarks, ideally data on the population or a random sample of Chicago properties would be used. No such dataset is available, however. Timely citywide property inventories with sufficient detail are generally not maintained. Lacking an available and ideal random sample, this paper examines two different samples of Chicago properties. The first is the sample of properties in the CHRS mentioned above. The CHRS might be thought of as a deliberate oversample of old, historically or culturally significant, and likely-to-become designated properties. The second is a set of all single-family attached houses (e.g., condos, townhomes) that were sold via the Multiple Listing Service (MLS) from19902000. While neither of these samples are the ideal, they both represent relevant subpopulations of structures.

A few differences between the CHRS and MLS datasets should be noted. The CHRS functions like cross-sectional inventory of historic properties in the city because the date each observation was taken is unknown. The MLS data, on the other hand, offer true time-series data on property sales over the course of a decade. This analysis establishes a baseline in 1990, exactly the start of the MLS data range and near to the end of the CHRS surveying effort. ${ }^{5}$ Table A1 in the Appendix provides definitions for

\footnotetext{
${ }^{5}$ Because of data limitations, we assume that CHRS data were collected by 1990. For CHRS properties surveyed after 1990, it is possible an endogeneity or sample selection bias might occur. The dependent variable (post-1990 designation status) might influence the independent variables from the CHRS dataset or even the likelihood of inclusion in the CHRS. If designated properties are more likely to be included, then
} 
variables used in the analysis and indicates from which datasets they derive. Summary statistics for the two samples of properties (CHRS and MLS) can be seen in Table A2.

In the theoretical model, all independent variables are collapsed into one variable, z. The discussion of the model considered various interpretations of that variable, including the historic nature of the structure, its cultural significance, its historic or cultural built environment and the income and other demographic characteristics of its neighborhood. The CHRS includes a set of color codes which contain some information on the historic or cultural significance. Red and Orange are the two codes used to describe nationally or locally significant structures, respectively. Colors further along the spectrum correspond - roughly - to less and less significant properties, with Blue and Purple assigned to structures with no significance, extensive alterations, or of such recent construction as to make their significance difficult to assess. Our other measure of historical significance is simply the year the structure’s construction was begun (begun), along with an interaction of this variable with its location within the zone affect by the Great Chicago Fire of 1871 (FireBegun). ${ }^{6}$ We also use a set of geographic variables to control for location in the Great Fire zone and for distance to the center of downtown Chicago, to water features, to industrial corridors, and to one of Chicago's historic boulevards. The latitude of the structure controls for location in the north side of the city.

inferences drawn from estimates using this sample may not be valid for the broader population of structures. For instance, oversampling designated-but-low-quality buildings might artificially lower the estimated effect of quality of designation. If designation status affects how surveyors recorded property information - or affected the building attributes directly - then classic endogeneity occurs. For example, designated buildings might receive higher quality scores than they would have without the prestige of designation, biasing upwards the estimated effect of quality on designation.

${ }^{6}$ The Great Chicago Fire of 1871 devastated much of the city core at the time, forcing a virtual rebuilding of this portion of the city. This puts an upper limit on building age in that area. Because the begun variable is missing for many observations, begun is coded with a 0 for all missing observations and a dummy variable (nobegun) is included to capture the mean effect of those buildings with missing begin values. See Alberini and Longo (2006) for an application of this approach. 
Other controls for building characteristics include the purpose of the structure (residential, commercial or other). Whether the CHRS property had a known tenant at the time of the survey (tenant) is also included as a proxy for lobbying interest and capacity. Actively used buildings may be better able to resist designation than vacant ones, just as purpose might indicate different owner interests.

Our proxies of cultural significance in the CHRS data are a set of dummy variables describing the extent to which information about the structure was known. These included dummy variables for whether the building was named (e.g., "the Robie House"), whether the architect was known, whether the building was assigned a specific type, or details, or described as an example of a particular architectural style. The historic or cultural environment is measured by a set of variables for the median year of construction in the structure's census block group (MedYear), the stock of pre-1990 designated landmarks in the block group (CountLmk), the percentage of the 1980 stock of pre-war housing that was demolished during the 1980's (PerOldLost) and the number of CHRS properties within a half mile of the structure (CountCHRS).

Finally, we have a set of neighborhood demographic variables. These include the average income $(\ln I n c)$, rent (InRent) and the logged population density (InPopDen) in our most basic models. In more fully specified models, we have included variables for the percent of the population with college degrees (perCol), the percent without high school degrees (perDrop), the percent of the population that is non-Hispanic, white (perWhite), and the percent of the households with incomes below $150 \%$ of the official poverty line (perPoor). 
Many of these variables are not available in the MLS data, except for structures that happen to be in both data sets. The MLS does offer a host of other structure variables which we use, including the square footage (Area), number of units in the building (units), the number of rooms, bedrooms and bathrooms (rooms, bedrms, and baths, respectively), the presence of a fireplace (firepl) or parking spot (parking) and the year of sale (saleyr). When analyzing the MLS data, we also include controls for whether the property was deemed culturally significant enough to be included in the CHRS and some of the CHRS variables.

Our two dependent variables are whether the structure (or unit) was designated as an individual landmark or included in a new historic district after 1990. While pre-1990 designation information is readily available, there is the chance that the designation status

could have affected the assessment of significance in or inclusion in the CHRS. Thus, by looking only at properties designated after the CHRS sample was selected, we choose a dependent variable that is safer from concerns about endogeneity.

\section{Results}

Table 1 presents the averages of the various outcome variables for the two data sets to give a sense of the extent of the programs. We see that in both samples post-1990 landmark designations are relatively rare. Such late designations make up only five percent of the CHRS sample (compared to 14\% pre-1990 designations) and only about one percent of the MLS sample (compared to about 2.5\% for pre-1990 designations). A much greater number of landmarks were designated before 1990. About five percent of the MLS sample is also in the CHRS sample, comprising about 3,600 observations. 
Among these CHRS observations in the MLS data set, nearly 20 percent are in landmark districts, and nearly seven percent were included in districts after 1990.

\section{[INSERT TABLE 1 HERE]}

The rest of this empirical section is split into three parts. First, using the CHRS data we present the "policy choice" model, where administrators choose whether to regulate, and how. In section 5.2, we add additional variables to the district model to assess the robustness of the estimated coefficients to the inclusion of additional explanatory variables. Section 5.3 compares the estimated coefficients from the CHRS district model to a comparable set of results using the MLS data, and adds some additional variables to the models using MLS data to assess how robust the estimated coefficients are to included variables.

\subsection{Policy Choice}

Table 2 reports the coefficients from the multinomial logit estimation of a model where administrators can assign a structure either no additional restriction (beyond city zoning and state and federal historical protections), include it in a district, or single out the structure for individual designation. ${ }^{7}$ The top panel of Table 2 reports the coefficients for the individual designations (relative to no designation at all), and the bottom panel reports coefficients for district designations (relative to no designation at all). Model 1 in Table 2 starts with a basic specification. Model 2 adds prior changes in neighborhood demographics in the middle column. A parsimonious model is specified because of the rarity of the 'individual designation’ policy choice.

\footnotetext{
${ }^{7}$ Strictly speaking, the model predicts whether structures are not designated, designated in a district, or individually designated at some point after 1990. Because a structure that was designated prior to 1990 cannot, in general, be re-designated during the 1990's, we drop these structures form the data set in all the regressions reported here.
} 


\section{[INSERT TABLE 2 HERE]}

Several variables have qualitatively similar coefficients across the two types of designation. These include the historical color codes (-),the variables for whether the structure was named $(+)$ or had a tenant $(-)$, neighborhood rent levels $(+)$, population density (+), whether the structure was in the zone affected by the Great Chicago Fire of $1871(+)$ and whether the structure was a residential property (-). ${ }^{8}$ That historical quality appears negatively related to the likelihood of historic designation is one of the more remarkable results for this analysis. The interpretation of the color code results are discussed in more detail below. There are several coefficients that differ between designation types. Some of the less interesting ones include the distance to the center of downtown and whether the property had a commercial use (both are insignificant for individual designations, significant and negative for districts).

Some important variables’ coefficients differ markedly by designation type. The negative coefficient on neighborhood income for district designation (relative to no designation) is significantly different from the smaller, insignificant negative coefficient for individual designation. If historic and cultural preservation is a normal good, these results are somewhat surprising. They suggest that individuals in high income neighborhoods do not want the restrictions placed on their own homes, and have the incentive and wherewithal to prevent such designations. The much smaller coefficient for income for the individual designation choice suggests that this incentive does not prevent the restrictions from being placed on their neighbors through individual designation, but neighborhood income does matter when the restrictions threaten their

\footnotetext{
${ }^{8}$ Some of these coefficients are insignificant for one of the designation types and not statistically different from one another at conventional levels. In those cases, we report the sign of the significant coefficient.
} 
own options through district designations. Similarly, increases in rents over the 1980's have significantly different effects in the two models, with negative effects on individual designation and positive or insignificant effects on district inclusion.

Another interesting difference in determinants is that of the date at which construction of the structure was begun. Newer structures are significantly less likely to be individually designated (relative to no designation at all), as expected. The effect of age on inclusion in a landmark district (rather than not designated at all) is non-existent. The difference in the coefficients is significant in Model 2. That individual structural age is important in determining individual designation but unimportant in determining inclusion in a district squares with intuition and the model: many non-historic properties are included in districts in order to minimize administrative costs, not to preserve them per se. Similar differences in coefficients also exist for the interaction between structure age and the Great Chicago Fire area.

Also differing between the individual and district determinants are the coefficients for the cultural environmental variables. These four variables are always statistically different from one another across designation types, and of opposite sign. They show that, conditional on a building's age, buildings in older neighborhoods (with smaller MedYear) are more likely to be designated as districts than individually, and vice versa. The percent of older homes demolished during the 1980's (PerOldLost), or the depletion of a neighborhood's historic or cultural resources, makes district designation less likely, as expected. It also makes the remaining buildings more likely to be singled out rather than be put in a district. Having additional protected landmarks in the vicinity (CountLmk) has an insignificant coefficient for individual designation relative to no 
designation, but makes district designation less likely relative to either alternative. The presence of multiple landmarks makes additional district preservation policy unneeded. Finally, the presence of more historic properties in the vicinity (CountCHRS) makes individual designation less likely (the structure will not be as special in the neighborhood) but makes district designation more likely (there is more heritage to preserve). These variables flesh out the decision criteria that administrators use in deciding whether to preserve and how to preserve.

These results show that the forces at work in the preservation of cultural resources cause administrators to pick and choose target properties, and to adjust the policy instrument to the case at hand, in ways consistent with the model. These decisions depend on the neighborhood context (demographic, economic and cultural) as well as the properties of the individual structure. Individual designations tend to happen to older properties in less historic neighborhoods, while districts tend to be in poorer neighborhoods with more historical resources.

\subsection{District models}

Because of the small number of individual designations after 1990, the multinomial logit analysis above restricts itself to a limited set of explanatory variables. We now turn to an analysis solely of the choice to designate a property in a district or not. The greater frequency with which properties become included in a district allows us to include a larger set of explanatory variables, examine these new variables’ coefficients and assess how stable the relationships described in part 5.1 are in the face of additional controls. Table 3 presents these results. The first column of results presents coefficients of a logit regression with additional color codes added, and shows that there are no 
qualitative changes from the multinomial logit models in Table 2. The next column includes some additional building details, while a third incorporates more geographic information. The rightmost column of results adds additional demographic and demographic trend variables. The inclusion of these variables makes some of the already-included variables’ coefficients change sign.

\section{[INSERT TABLE 3 HERE]}

The coefficients of added building characteristics generally show that having more information about a building makes it more likely to be designated. These building characteristics are our main proxy of cultural significance, so these results suggest (along with those results in Table 2) that more culturally significant buildings (e.g., greater fame or notoriety of the building or its architect, representativeness of its architectural style) are more likely to be designated, as the theory predicts. Adding these variables to the model causes the named and Fire coefficients to become insignificant, and the residential use dummy variable coefficient to become significantly negative. Also, including these cultural variables makes the begun variable become significantly negative. The construction date's insignificance in the model with fewer cultural significance measures shows that the interplay between a building's cultural and historical significance is important. Landmark designations in Chicago appear to be about more than just history cultural dimensions matter as well, and the effects of one may mask the other in an improperly specified model.

Adding the geographic information shows that a more northern location is associated with a greater likelihood of district designation, as does being located further away from industrial corridors or bodies of water (e.g., Lake Michigan, Chicago River). 
Adding these variables causes the Fire dummy variable to become significantly negative along with the dummy for having no information about construction dates, but the residential use variable goes back to positive. Furthermore, these geographic variables drive the 1990 rental rates coefficient and the percent of lost old residences coefficient into insignificance. It would be difficult to generalize much from the effect of these geographic controls on the other variables. The geographic coefficients as well as their effects on the other coefficients says more about the specific historical development of the city of Chicago than anything else.

Finally, the additional demographic information yields a positive association with the percent white in 1990 and the 1980-1990 change in the percent college educated. The percent college educated in 1990, the changes in the poverty rate and percent white over the 1980 's are all associated with lower probability of being designated. Adding these variables has big effects on the previously-included demographic variables, as might be expected. When the new demographic variables are added, 1990 rental rates and the change in neighborhood income from 1980-1990 become significant and negative, while 1990 neighborhood income levels becomes insignificant, as does the dummy variable for whether the CHRS data set included information on the style of the structure. However, the percentage of older homes demolished during the 1980's becomes significantly negative again, as in previous models.

The three demographic variables which change signs in the presence of the new demographic controls (InRent, InInc and $d \ln I n c$ ) might be expected to change sign in the presence of the additional demographic controls. For instance, while income changes sign from negative to positive, it is only in the presence of the strong negative coefficient 
of the college variable that this occurs. The same is true for the switch of the coefficient on income changes and the sign of the coefficient of changes in college education: the income variable changes sign, but only in the presence of the new college variable, which takes the sign that the income variable had in the college variable's absence. The interpretations loaded on the income variable in part 5.1 could thus now be leveled on a “class” variable, as represented by the college education levels in the neighborhood, and these results support the idea that education, class and the cultural tastes and attitudes associated with them are more important than income per se. ${ }^{9}$

While the signs of some of these coefficients are interesting in their own right, another point of this exercise has been to assess the robustness of the conclusions from part 5.1. Comparing the first and last columns of Table 3 gives a sense of which coefficients changed. In general, the color codes, geographical variables (except for the Fire variable) and the building information show fairly stable results across all these models. While some variables change significance, only three (Fire, InRent and dInInc) go from significant in one direction to significant in another because of the addition of control variables.

The most important and robust set of results are those relating to the historical and cultural environment that these structures inhabit. In almost every model, these variables retain their sign and significance, telling a consistent story. Structures in newer neighborhoods are less likely to be included in a district (recall, however, that they were more likely to be individually designated), as are structures in neighborhoods that have

\footnotetext{
${ }^{9}$ The connection between income and education as determinants of demand for heritage preservation, and cultural goods in general, is discussed in greater detail elsewhere (e.g., Bourdieau 1984). This is another instance of education being a better predictor of cultural demand than income (e.g., Heilbrun and Gray 2001, Whitehead and Finney 2003, Alberini and Longo 2006).
} 
lost substantial percentages of their older, more culturally significant structures, or where there already exists substantial amounts of protected culturally significant properties. However, properties near a higher density of significant buildings (those with more CHRS properties in the vicinity) are more likely to be designated as a district to preserve that dense cultural fabric. ${ }^{10}$ So, while the results are fairly robust in general, with respect to the historical and cultural environmental variables, they are extremely robust. The variables describing the structure's own cultural significance (named, architect, typed, styled, detailed) are also quite robust, reinforcing the message from the multinomial analysis that more culturally significant structures are more likely to be designated in districts, holding the historic significance and other factors constant.

\subsection{Comparing MLS and CHRS results}

The sampling of primarily historic properties in the CHRS data offers an interesting population to examine. However, because the CHRS data does not represent anything like a random sample of properties in a city, the ability to generalize the results cannot be taken for granted. Here we compare the results obtained from the CHRS data set with results from a MLS data set comprising all sales listed in the Multiple Listing Service of single-family attached housing in Chicago over the 1990's. Comparing results between the MLS sample and the CHRS sample gives us a sense of the sensitivity of our findings to sample selection. While neither of these samples is ideal (the CHRS is too concentrated on more historic structures while the MLS is too concentrated on residential sales) consistency of estimates across samples reassures us of the strength of the

\footnotetext{
${ }^{10}$ If CountCHRS distinguished between red and orange CHRS properties and other CHRS properties, the unrestricted model above would show (not reported here) that it is count of red and orange properties nearby that drives this effect.
} 
relationships we are uncovering here. Table 4 shows results for very similar models using the CHRS data and the MLS data in the first two columns. It is worth noting that when one restricts the MLS sample to have similar structure age profile to the CHRS (looking only at buildings built before 1974), the results do not change substantively.

\section{[INSERT TABLE 4 HERE]}

Focusing on the changes that happen as we move from the CHRS to the MLS sample, we see that some coefficients change sign, although only two (InInc and InPopDen) change sign significantly (that is, from significantly positive to significantly negative). In the CHRS sample, increases in population density are negatively associated with district designation, while they are positively associated with designation in the MLS sample. The median income in 1990 also changes from significantly negative to significantly positive as we change samples. However, this variable had slightly unstable coefficients across specifications in the CHRS sample as well. These are very important neighborhood indicators as one represents population growth and the other offers a fair proxy for the economic status of the neighborhood. Several other variables change sign, but never from significant in one direction to significant in another direction. Of the 28 variables included in the equation, only 7 show instability, and 21 retain the same sign and significance regardless of the sample. Throughout the paper, we have focused on the coefficients on the variables measuring the historical and cultural environment of the structure. One of these variables (PerOldLost) becomes insignificant in the MLS sample. ${ }^{11}$ The rest of the interesting historical environment variables are consistent with what came before.

\footnotetext{
${ }^{11}$ Interestingly, the percentage of old housing lost during the 1990s is positive and significant when included in a similar regression. Because this variable is endogenous, we do not report any such
} 
The last two columns of results in Table 4 use the MLS sample, but add control variables. We add a number of individual structural characteristics available in the MLS data, but not in the CHRS. Of these, the living area is positively associated with district designation while the number of bathrooms, access to a parking space, and the year of sale are negatively associated with district designation. The last of these coefficients suggests that attached housing sales are increasingly in non-landmark districts over the 1990s. The size of the building (units) is inversely related to the likelihood of district designation throughout its range in both the last two columns. The addition of the unit characteristics also drives the CountLmk coefficient insignificant, although it retains its negative sign. As with the change in significance of PerOldLost, it is important to remember that this coefficient pertains holding the median age of neighboring structures and the number of nearby CHRS properties constant.

The negative coefficient for certain color codes (e.g., orange) remains in the MLS sample. This unexpected result suggests several possible explanations. First, most of the most significant heritage resources were already designated landmarks by 1990. The "orange" properties not already designated in the first 22 years of the program likely remain undesignated for some other reason. It might be some unobservable factor (e.g., existing easements, politically powerful owners) that either makes their designation too costly or redundant. After the administrator has already "cherry-picked”, properties of less-significant color codes (which lack these unobservable factors) appear more likely to become designated. Second, at least for the properties not yet designated by 1990, the

regressions here. Its significance could be interpreted cynically (that preservation policies lead owners to demolish houses). Another interpretation is that high rates of demolition increase the demand for preservation by neighbors, leading administrators to preserve areas "threatened" by development. Much hinges on the timing of the preservation and the demolition, which we cannot address here. 
coding criteria in the CHRS apparently diverge substantially from the many factors (e.g., history, culture, economic development, art, aesthetics) considered by Landmarks Commission in Chicago (2007). The CHRS measure for quality need not be the same as subsequently used by the administrator. Third, and related to the first two, is that the effects in Tables $2-4$ are conditional on other control variables. For CHRS structures, individual designations are significantly and positively (unconditionally) correlated with red and yellow properties, significantly negatively correlated with green, and not significantly correlated with orange (the modal category). Finally, for codes other than red or orange (the most significant codes), the codes partly reflect modifications that have occurred to the property. The historic-but-modified property may be more likely than historic-and-authentic to merit designation of any sort because the modification may signal that the remaining heritage resource is at greater risk (raising $N_{r}$ ) or may signal that the owner has already made the desired modernization (lowering $P_{r}$ ).

In general, moving form the CHRS to the MLS does not create large changes in the estimated coefficients. Comparing the first column of results in Table 4 with the last, we see that of the 28 common coefficients between the MLS and CHRS datasets, only nine change, and only two change from significant in one direction to significant in another. While two of our four historical and cultural environmental variables become insignificant, they retain their sign. Furthermore, the proxies for historic value (the color codes and begun) are generally robust, as is our proxy for cultural significance (named, although it is important to keep in mind that this variable depends on MLS observations that overlap with the CHRS dataset, so its consistency should not be surprising). All in 
all, the results paint a broadly consistent picture of the designation process across specifications and across samples.

\section{Conclusions}

This paper endeavors to shed light on the process of historical and heritage preservation, using the case of Chicago's landmarks program. To that end, we develop a simple model of administrative choice, and test that model on two datasets. We find sensible patterns in the data, both in terms of the kinds of properties designated and the type of designation chosen. An implication of the model is that the presence or absence of landmarks in a neighborhood cannot be taken as a simple proxy for demand for cultural assets. The designation of a structure as a landmark is the result of an interplay amongst the demands of neighbors, the resistance of owners and the administrative behavior of the regulator. Designation choices therefore reflect more than community members’ or experts’ assessments of (architectural, historical, etc.) quality from an inventory of historical resources. Stand-out properties in newer neighborhoods tend to be protected via single designation, while properties in older neighborhoods tend to be protected as part of a large district. We find evidence that being older makes a structure more likely to be individually designated. Additional cultural significance appears to be positively correlated with both individual designation and district or group designation. Among historical buildings, a structure's age is weakly related to the likelihood of inclusion in a landmark district unless other cultural variables are controlled for. The results shed light on the administrative decisions historical and cultural preservation regulators make, and their selection of policy instruments in a major American city with active preservation policy. 
Further analysis of the robustness of the findings to changes in specification finds that the results are on the whole quite robust. Unfortunately, this analysis is restricted to the district model because of the scarcity of individual designations. Most of the independent variables are robust to specification changes. Those describing the historical environment of the structure are especially robust, telling a consistent story across many specifications. Structures in older neighborhoods with fewer protections in place and more historical resources are more likely to be protected as districts. While this may seem intuitively obvious, the robustness of these coefficients in the district models gives us additional confidence in the coefficients from the more parsimonious multinomial logit models. This further highlights the choices historical preservationists face among policy instruments and the way in which different policies are applied. Hardly the final word in explaining why we choose to preserve what we do, this analysis is among the first to quantitatively and systematically explain historic designation choices. Additional methods and data would complement this initial investigation well.

Latent in the model is a consideration of the supply of historical resources in an area, how that supply might evolve over time, and how policy might be used to affect that evolution. Many discussions take a static view, assuming that the supply of heritage resources is fixed and only depletable over time. From a resource economics standpoint, whether historical and cultural resources are renewable is a crucial distinction. Many policies appear to cast heritage as a nonrenewable resource, making any changes to the stock of heritage irreversible. Future economic inquiry and empirical analysis of policy impacts would do well to view these historic preservation policies in this light and examine how the policies are implemented as well as their broader (and possibly 
unintended) consequences. It might be the case, for instance, that the threat of preservation policies could spur owners to redevelop preemptively, as in Turnbull (2002). Whether such effects exist, and whether preservation policies are indeed effective in actually preserving historical resources are issues the literature has yet to take up.

This paper also assesses the usefulness of the CHRS by comparing its results with findings from a large sample of all sales of attached homes in Chicago over the 1990s. Such samples of sold properties form an important part of the literature assessing the effects of policy on the value of housing. We find that the results from the CHRS are fairly robust, with only a few coefficients changing signs significantly across samples. It seems that the revealed preferences for preservation designation among the inventory of historically and culturally significant properties in Chicago are not altogether different than the decision criteria used for a sample of properties selected less overtly for historical significance. The combination of the historical information with the sales information raises the possibility in future work of examining the complicated interplay among the value of homes, their historical and cultural significance and the positive externality they bestow upon their neighbors. As many of the variables used in this analysis would presumably also be significant in a hedonic price equation, they will likely not serve as valid instruments for policy choice. However, this paper highlights the strong possibility of endogeneity bias in the estimation of the effects of designation policy on the value of properties designated. Similar endogeneity problems might also complicate the measurement of external effects of such policies on neighboring properties not directly affected by the regulation. Such endogeneity problems are extremely important since these external effects of preservation policy are a primary 
justification for preservation policies. Any examination of the effects of these policies must first be grounded in a solid understanding of the causes of these policies.

While we find consistent and easily interpretable results for the variables measuring the historical and cultural environment of a structure, and many of the structure's own characteristics, the results are less consistent with regards to some neighborhood-level factors. Future work might fruitfully examine exactly how neighborhood demographics and preservation policy affect one another. Whether designation is more likely in rich or poor, growing or shrinking, expensive or affordable, gentrifying or disintegrating neighborhoods is interesting for a variety of reasons. As these policies restrict property owners, concerns over the economic justice of the decisions might be raised. The causal interaction between neighborhood demographics and preservation policy also offer a window into the decision making of preservation program administrators, and the effects of those decisions on the neighborhoods they regulate.

\section{References}

Ahlfeldt, G.M. \& W. Maennig (2009). Substitutability and Complementarity of Urban Amenities: External Effects of Built Heritage in Berlin. Forthcoming in Real Estate Economics 37 (6).

Alberini, A., \& Longo, A. (2006). Combining the Travel Cost and Contingent Behavior Methods to Value Cultural Heritage Sites: Evidence from Armenia. Journal of Cultural Economics, 30 (4), 287-304.

Bourdieu, P. (1984). Distinction. Cambridge: Harvard University Press.

City of Chicago (2004). Chicago Landmarks: General Information. http://www.cityofchicago.org/Landmarks/GeneralInfo.html 
Commission on Chicago Landmarks (1996). Chicago Historic Resources Survey: An Inventory of Architecturally and Historically Significant Structures. Chicago: The Department.

Commission on Chicago Landmarks (2007). Landmarks Ordinance with Rules and Regulations of the Commission on Chicago Landmarks. Chicago: City of Chicago.

http://www.cityofchicago.org/Landmarks/pdf/Landmarks_Ordinance.pdf. Accessed 28 April 2008.

Coulson, N. E., \& Lahr, M. L. (2005). Gracing the Land of Elvis and Beale Street: Historic Designation and Property Values in Memphis. Real Estate Economics, 33(3), 487-507.

Coulson, N. E., \& Leichenko, R. M. (2004). Historic Preservation and Neighbourhood Change. Urban

Studies, 41(8), 1587-1600.

Coulson, N. E., \& Leichenko, R. M. (2001). The Internal and External Impact of Historical Designation on Property Values. Journal of Real Estate Finance and Economics, 23(1), 113-124.

Cyrenne, P., Fenton, R., \& Warbanski, J. (2006). Historic Buildings and Rehabilitation Expenditures: A Panel Data Approach. Journal of Real Estate Research, 28(4), 349-379.

Heilbrun, J., \& Gray, C. M. (2001). The Economics of Art and Culture. New York: Cambridge University Press.

Listokin, D., \& Lahr, M. L. (1997). Economic Impacts of Historic Preservation. New Jersey: New Jersey Historic Trust.

Listokin, D., Listokin, B., \& Lahr, M. L. (1998). The Contributions of Historic Preservation to Housing and Economic Development. Housing Policy Debate, 9(3), 431-478.

Longo, A., \& Alberini, A. (2006). What Are the Effects of Contamination Risks on Commercial and Industrial Properties? Evidence from Baltimore, Maryland. Journal of Environmental Planning and Management, 49(5), 713-737.

Mason, R. (2005). “Economics and Historic Preservation: A Guide and Review of the Literature.” Brookings Institution Discussion Paper, September 2005.

Metrick, A., \& Weitzman, M. L. (1998). Conflicts and Choices in Biodiversity Preservation. Journal of Economic Perspectives, 12(3), 21-34.

Noonan, D. S. (2007). Finding an Impact of Preservation Policies: Price Effects of Historic Landmarks on Attached Homes in Chicago, 1990-1999. Economic Development Quarterly, 21(1), 17-33. 
Schuster, J. M. (2002). Making a List and Checking It Twice: The List as a Tool of Historic Preservation. (Working Paper No. 14). Chicago: The Cultural Policy Center at the University of Chicago. http://culturalpolicy.uchicago.edu/workingpapers/Schuster14.pdf. Accessed 24 April 2008.

Turnbull, G. (2002). Land Development under the Threat of Taking. Southern Economic Journal, 69(2), 468-501.

Whitehead, J. C., \& Finney, S. S. (2003). Willingness to Pay for Submerged Maritime Cultural Resources. Journal of Cultural Economics, 27(3-4), 231-240. 


\title{
Appendix
}

\author{
Table A1: Variable Descriptions \\ Variable \\ Definition \\ $D B_{90}$ \\ dummy variable taking a 1 if property is or was in a building designated a \\ landmark itself (non-district) after 1990 \\ $D D_{90} \quad$ dummy variable taking a 1 if property was in a landmark district designated \\ after 1990 \\ red dummy variable (CHRS code for historical or architectural significance at the \\ city, state, or national level) \\ orange dummy variable (CHRS code for significance at the community level) \\ yellow \\ dummy variable (CHRS code for significance lacking despite good physical \\ integrity) \\ yellow-grn dummy variable (CHRS code for a lack of individual significance and an \\ alteration like artificial siding) \\ green dummy variable (CHRS code for over 10\% alteration from the original \\ appearance) \\ purple dummy variable (CHRS code for no significance and extensive alterations) \\ blue \\ dummy variable (CHRS code for properties built after 1940, indicates the \\ structure was too recent for evaluation) \\ begun CHRS sample: year construction began (missing values replaced with a '0') \\ MLS sample: year built, imputed ${ }^{\text {a }}$ \\ nobegun $\quad$ CHRS sample: dummy variable taking a 1 if yearbuilt is 0 . $^{\mathrm{b}}$ \\ named \\ dummy variable (CHRS has entry for "historic name" field) \\ tenant \\ architect \\ dummy variable (CHRS has entry for "common name/major tenant” field) \\ type \\ style \\ dummy variable (CHRS has entry for "architect" field) \\ dummy variable (CHRS has entry for "building type” field) \\ details \\ dummy variable (CHRS has entry for "style" field) \\ dummy variable (CHRS has entry for "style: details" field) \\ purpose: Res \\ purpose: Com \\ dummy variable (CHRS codes as various residential types) \\ dummy variable (CHRS codes as commercial, club, bank, gas station, hotel, \\ theater) \\ InArea $\quad \ln \left(\right.$ area of housing unit in feet ${ }^{2}$ ), MLS sample only \\ units \\ rooms \\ number of units in the building, MLS sample only \\ bedrms \\ baths \\ firepl \\ parking \\ saleyr \\ InICDist \\ InWaterDist \\ InCTADist \\ $\operatorname{lnBlvdDist}$ \\ lnCBDDdist \\ latitude \\ fire \\ number of rooms, MLS sample only \\ number of bedrooms, MLS sample only \\ number of baths, MLS sample only \\ number of fireplaces, MLS sample only \\ dummy variable (MLS data indicates a parking spot present), MLS only \\ year of sale of the observation, MLS sample only \\ $\ln$ (distance to industrial corridor) \\ $\ln$ (distance to nearest river or lake) \\ $\ln$ (distance to nearest CTA rail line) \\ $\ln$ (distance to nearest "boulevard") \\ $\ln$ (distance to State \& Monroe downtown) \\ decimal degrees north \\ dummy variable taking a 1 if property in one of two downtown community \\ areas that hosted that Great Chicago Fire of 1871 \\ PerOldLost Reduction from 1980 to 1990 in number of homes built before 1939, as a
}




\begin{tabular}{|c|c|}
\hline Variable & Definition \\
\hline & percent of pre-1939 homes in $1980^{*}$ \\
\hline dlnInc98 & ln(median household income, 1990/median household income, 1980)* \\
\hline dlnRent98 & $\ln \left(\right.$ median contract rent, 1990/median contract rent, 1980) ${ }^{*}$ \\
\hline dlnPopDen & population density (pop/mi $\left.{ }^{2}\right), 1990$ - population density, 1980* \\
\hline dperWhite & percent white population, 1990 - percent white population, $1980^{*}$ \\
\hline dperCol & percent college degrees, 1990 - percent college degrees, $1980^{*}$ \\
\hline dperPoor & $\begin{array}{l}\text { percent below } 150 \% \text { poverty line, } 1990 \text { - percent below } 150 \% \text { poverty line, } \\
1980^{*}\end{array}$ \\
\hline dperDrop & percent high school drop out, 1990 - percent high school drop out, 1980* \\
\hline $\ln I n c$ & $\ln \left(\right.$ median household income, 1990) ${ }^{*}$ \\
\hline lnRent & $\ln \left(\right.$ median contract rent, 1990) ${ }^{*}$ \\
\hline InPopDen & population density $\left(\mathrm{pop} / \mathrm{mi}^{2}\right), 1990^{*}$ \\
\hline perWhite & percent white population, $1990^{*}$ \\
\hline perCol & percent college degrees, $1990^{*}$ \\
\hline perPoor & percent below $150 \%$ poverty line, $1990^{*}$ \\
\hline perDrop & percent high school drop outs, $1990^{*}$ \\
\hline CountLmk & count of designated landmarks (as of 1990) within $1 / 8^{\text {th }}$ mile (approx. 1 block) \\
\hline CountCHRS & count of CHRS properties within $1 / 8^{\text {th }}$ mile (approx. 1 block) \\
\hline MedYear & median Year of consdtruction of homes in Block group, $1990^{*}$ \\
\hline \multicolumn{2}{|c|}{$\begin{array}{l}{ }^{a} \text { Missing yearbuilt values in MLS data imputed using the housing attributes above, ten others (e.g., areas of } \\
\text { living room and bedroom, story number of unit, basement, garage), and additional geographic controls. } \\
\text { See Noonan (2007) for a more detailed description. } \\
\text { b For a discussion of this approach to dealing with missing data, see Longo and Alberini (2006) } \\
{ }^{c} \text { Median year built from Census data for } 1990 \text { for CHRS samples and from a linear interpolation of } 1990 \\
\text { and } 2000 \text { Census values (based on year-of-sale) for MLS sample.. } \\
\text { * Values for the property's block-group, from Geolytics }{ }^{\mathrm{TM}} \text {. }\end{array}$} \\
\hline
\end{tabular}

Table A2: Descriptive Statistics

\begin{tabular}{|r|ccc|ccc|}
\hline \multirow{2}{*}{ Variable } & \multicolumn{3}{|c|}{ CHRS Sample } & \multicolumn{3}{c|}{ MLS Sample } \\
\hline CHRSprop & 17366 & 1.000 & 0.000 & 74124 & 0.050 & 0.219 \\
red & 17366 & 0.010 & 0.098 & 0 & -- & -- \\
orange & 17366 & 0.557 & 0.497 & 74124 & 0.041 & 0.198 \\
yellow & 17366 & 0.144 & 0.351 & 0 & -- & -- \\
yellow-grn & 17366 & 0.015 & 0.123 & 0 & -- & -- \\
green & 17366 & 0.239 & 0.427 & 74124 & 0.005 & 0.070 \\
purple & 17366 & 0.003 & 0.058 & 0 & -- & -- \\
blue & 17366 & 0.013 & 0.115 & 0 & -- & -- \\
begun* & 8125 & 1904.550 & 16.901 & 66419 & 1957.943 & 26.992 \\
nobegun & 17366 & 0.532 & 0.499 & 0 & -- & -- \\
named & 17366 & 0.147 & 0.354 & 74124 & 0.009 & 0.093 \\
tenant & 17366 & 0.083 & 0.277 & 0 & -- & -- \\
architect & 17366 & 0.291 & 0.454 & 0 & -- & - \\
type & 17366 & 0.666 & 0.472 & 0 & -- & -- \\
\cline { 6 - 7 }
\end{tabular}




\begin{tabular}{|c|c|c|c|c|c|c|}
\hline style & 17366 & 0.397 & 0.489 & 0 & -- & -- \\
\hline details & 17366 & 0.732 & 0.443 & 0 & -- & -- \\
\hline purpose: Res & 18441 & 0.349 & 0.477 & 0 & -- & -- \\
\hline purpose: Com & 18441 & 0.062 & 0.241 & 0 & -- & -- \\
\hline InArea & 0 & -- & -- & 73787 & 7.073 & 0.442 \\
\hline units & 0 & -- & -- & 71222 & 155.874 & 237.368 \\
\hline rooms & 0 & -- & -- & 73491 & 4.677 & 1.817 \\
\hline bedrms & 0 & -- & -- & 70063 & 1.906 & 0.806 \\
\hline baths & 0 & -- & -- & 74096 & 1.531 & 0.659 \\
\hline firepl & 0 & -- & -- & 74124 & 0.295 & 0.504 \\
\hline parking & 0 & -- & -- & 74124 & 0.172 & 0.377 \\
\hline saleyr & 0 & -- & -- & 74122 & 1995.429 & 2.804 \\
\hline InICDist & 16710 & -4.698 & 1.198 & 0 & -- & -- \\
\hline InWaterDist & 16977 & -4.610 & 0.746 & 74124 & -0.448 & 0.890 \\
\hline InCTADist & 16977 & -5.208 & 1.317 & 74124 & -0.729 & 1.124 \\
\hline InBlvdDist & 16977 & -4.198 & 1.475 & 0 & -- & -- \\
\hline InCBDDdist & 16977 & -2.715 & 0.707 & 74124 & 1.617 & 0.903 \\
\hline latitude & 17366 & 40.929 & 6.196 & 74124 & 41.928 & 0.051 \\
\hline fire & 17366 & 0.062 & 0.241 & 74124 & 0.229 & 0.420 \\
\hline dlnInc98 & 16580 & 0.606 & 0.463 & 72385 & 0.773 & 0.502 \\
\hline dlnRent98 & 16321 & 0.870 & 0.273 & 72008 & 0.845 & 0.325 \\
\hline dlnPopDen & 16705 & -0.096 & 0.312 & 72835 & 0.031 & 0.248 \\
\hline dperWhite & 16705 & -0.017 & 0.144 & 72835 & 0.008 & 0.172 \\
\hline dperCol & 16665 & 0.078 & 0.116 & 72835 & 0.152 & 0.153 \\
\hline dperPoor & 16588 & -0.009 & 0.162 & 72525 & -0.048 & 0.165 \\
\hline dperDrop & 16665 & -0.098 & 0.119 & 76119 & -0.114 & 0.141 \\
\hline $\operatorname{lnIn} c$ & 16595 & 10.054 & 0.642 & 72632 & 10.453 & 0.451 \\
\hline InRent & 16333 & 6.066 & 0.393 & 72077 & 6.359 & 0.317 \\
\hline InPopDen & 16715 & 9.663 & 1.019 & 73013 & 10.073 & 1.167 \\
\hline perWhite & 16715 & 0.398 & 0.359 & 73013 & 0.719 & 0.235 \\
\hline perCol & 16715 & 0.259 & 0.255 & 73013 & 0.474 & 0.226 \\
\hline perPoor & 16638 & 0.342 & 0.232 & 72772 & 0.180 & 0.145 \\
\hline perDrop & 16715 & 0.338 & 0.227 & 76302 & 0.156 & 0.149 \\
\hline PerOldLost & 16722 & 0.077 & 0.786 & 72227 & 0.030 & 0.577 \\
\hline CountLmk & 18441 & 0.398 & 0.822 & 74124 & 0.573 & 0.912 \\
\hline CountCHRS & 16977 & 38.516 & 36.592 & 115648 & 12.938 & 20.975 \\
\hline MedYear & 16630 & 1945.526 & 11.028 & 73013 & 1952.939 & 13.477 \\
\hline
\end{tabular}


Table 1: Landmark status in the two data sets.

\begin{tabular}{|lrr|lrr|}
\hline \multicolumn{2}{l}{ CHRS } & \multicolumn{3}{c|}{ MLS } \\
& Prop. & Freq. & & Prop. & Freq. \\
\hline All Landmarks & 0.1994 & 3462 & CHRS Property & 0.0504 & 3603 \\
Pre-1990 & 0.1420 & 2466 & District Ever & 0.0353 & 2528 \\
Post-1990 & 0.0574 & 996 & District Post-1990 & 0.0088 & 627 \\
Post-1990 Districts & 0.0569 & 966 & & & \\
Post-1990 Individual & 0.0018 & 30 & & & \\
Obs & 1.0000 & 17366 & Obs & 1.0000 & 71534 \\
\hline
\end{tabular}

Table 2: Multinomial logit regression results.

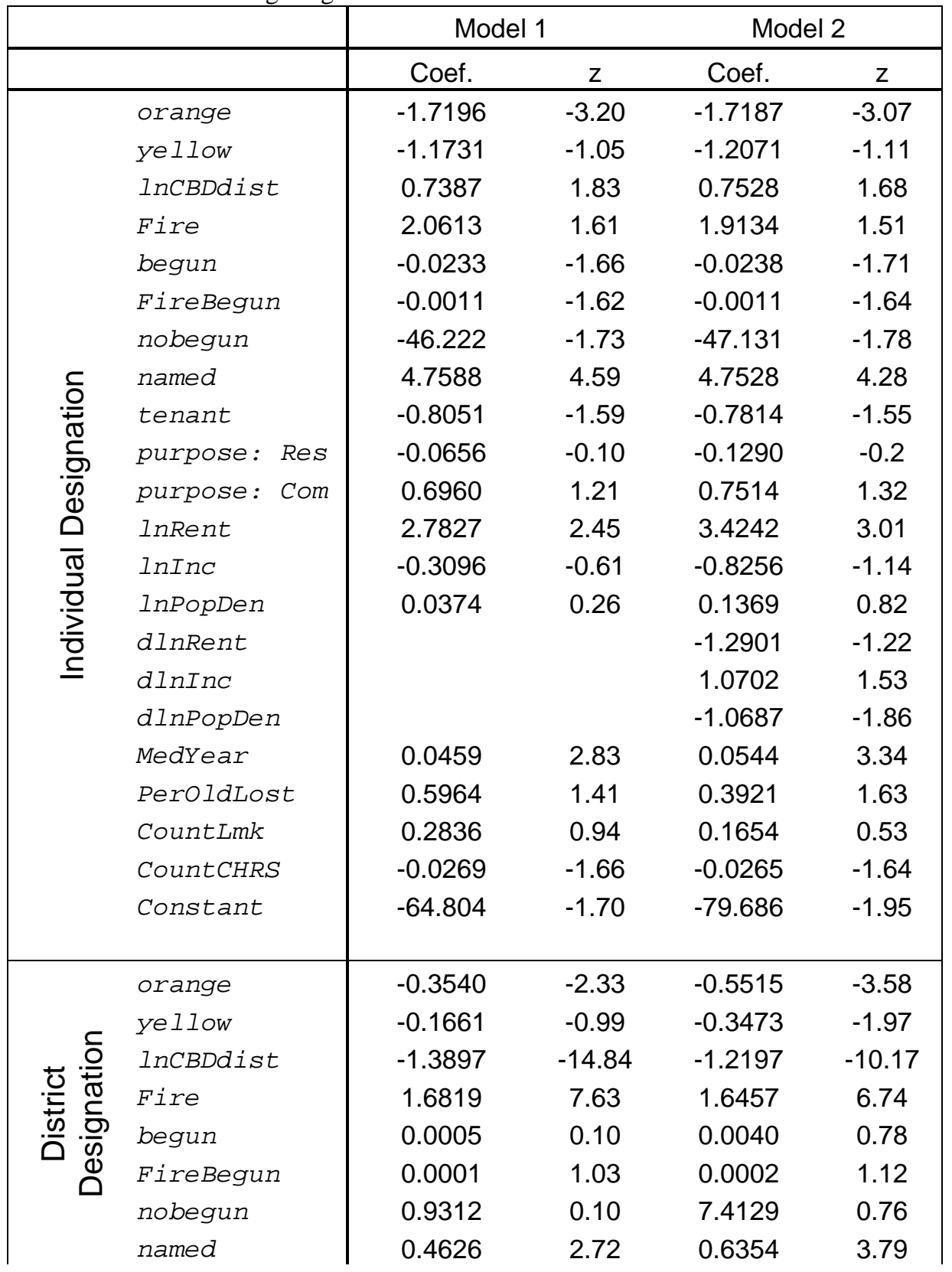




\begin{tabular}{|c|c|c|c|c|}
\hline tenant & -0.5468 & -2.27 & -0.4987 & -2.15 \\
\hline purpose: Res & -0.1327 & -0.99 & 0.1679 & 1.25 \\
\hline purpose: Com & -0.7223 & -3.12 & -0.5104 & -2.3 \\
\hline InRent & 1.3298 & 7.07 & 2.5855 & 10.36 \\
\hline $\ln \operatorname{Inc}$ & -1.5466 & -10.93 & -3.2195 & -15.59 \\
\hline InPopDen & -0.0012 & -0.03 & 0.3042 & 6.47 \\
\hline dlnRent & & & 0.3331 & 1.46 \\
\hline dlnInc & & & 1.7973 & 10.88 \\
\hline dlnPopDen & & & -0.9432 & -6.91 \\
\hline MedYear & -0.0266 & -6.24 & -0.0369 & -8.55 \\
\hline PeroldLost & -0.1643 & -5.01 & -0.3611 & -12.32 \\
\hline Count Lmk & -1.9133 & -19.42 & -1.6100 & -17.42 \\
\hline CountCHRS & 0.0612 & 37.58 & 0.0586 & 33.45 \\
\hline Constant & 48.782 & 3.84 & 67.030 & 5.08 \\
\hline Pseudo R-sq & \multicolumn{2}{|c|}{0.4829} & \multicolumn{2}{|c|}{0.5129} \\
\hline Observations & \multicolumn{2}{|c|}{13,837} & \multicolumn{2}{|c|}{13,832} \\
\hline Log-likelihood & \multicolumn{2}{|c|}{$-1,869.6821$} & \multicolumn{2}{|c|}{$-1,760.6685$} \\
\hline
\end{tabular}


Table 3: Robustness of district model coefficients to additional controls.

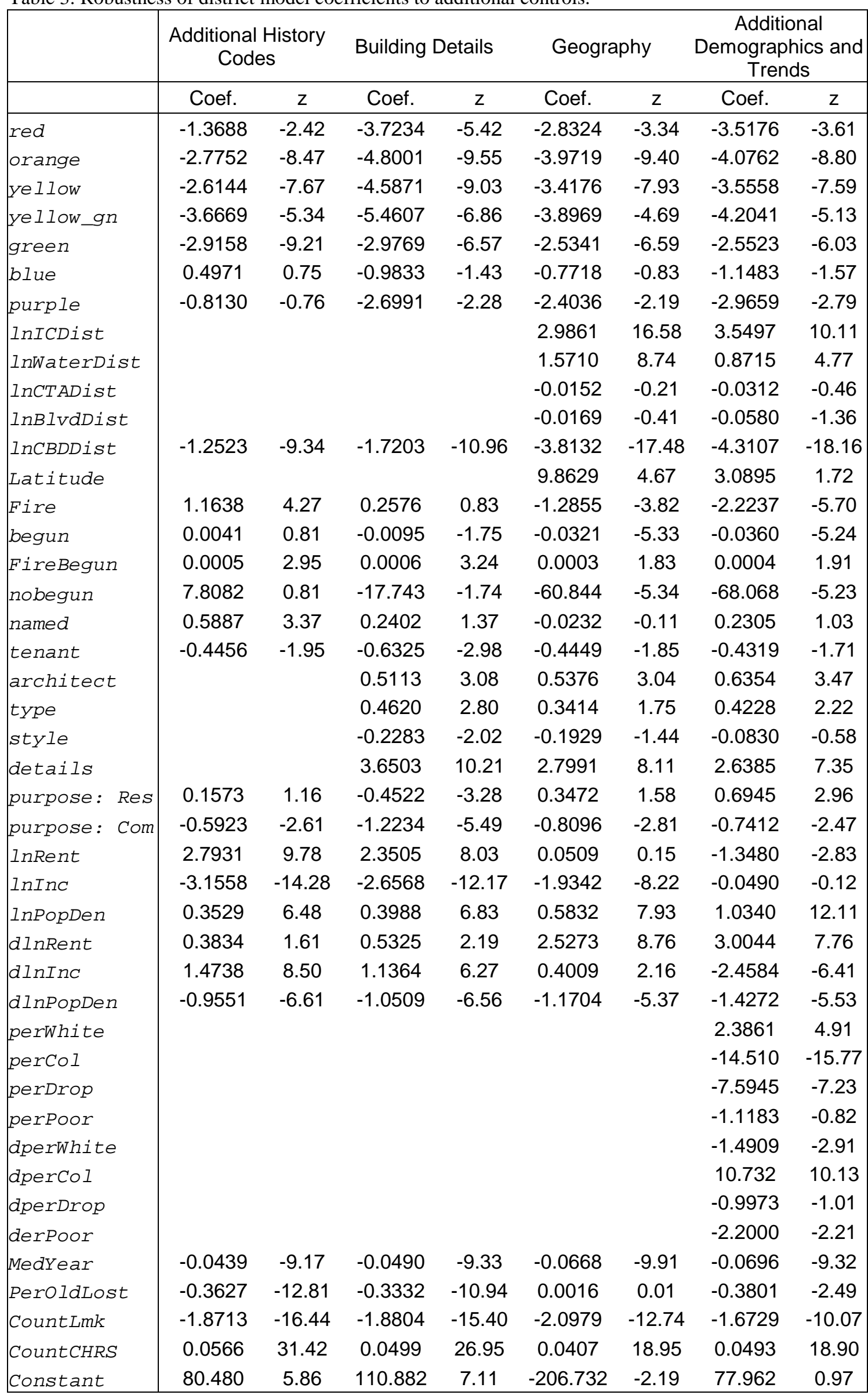




\begin{tabular}{|l|cccc|}
\hline Pseudo R-sq & 0.5433 & 0.5814 & 0.6748 & 0.7109 \\
Observations & 13,832 & 13,832 & 13,602 & 13,602 \\
Log likelihood & $-1,562.8301$ & $-1,432.2516$ & $-1,107.5842$ & -984.66176 \\
\hline
\end{tabular}


Table 4: District designation models: robustness to different samples.

\begin{tabular}{|c|c|c|c|c|c|c|}
\hline & \multicolumn{2}{|c|}{ CHRS } & \multicolumn{4}{|c|}{ MLS } \\
\hline & Coef. & z & Coef. & z & Coef. & z \\
\hline CHRSprop & & & 1.5850 & 6.71 & 1.3928 & 5.98 \\
\hline CHRS $^{*}$ orange & -0.9231 & -6.61 & -1.5503 & -5.24 & -1.4431 & -5.09 \\
\hline CHRS*green & -1.4072 & -7.92 & -0.5753 & -1.49 & -0.3129 & -0.70 \\
\hline InWaterDist & 1.1900 & 9.26 & $\odot .3417$ & 1.87 & 0.5430 & 2.55 \\
\hline InCTADist & 0.4147 & 6.00 & $\odot .5938$ & 9.19 & 0.4681 & 6.47 \\
\hline InCBDDist & -2.5312 & -14.58 & -0.6342 & -2.89 & -0.8673 & -4.08 \\
\hline Latitude & -0.1352 & $-\odot . \odot 9$ & -9.6841 & -4.12 & -11.836 & -4.82 \\
\hline Fire & 0.2019 & 0.76 & -11.892 & -1.80 & -11.097 & -1.44 \\
\hline begun & -0.0148 & -2.62 & -0.0130 & -5.48 & -0.0114 & -4.32 \\
\hline FireBegun & 0.0003 & 2.07 & 0.0064 & 1.90 & 0.0058 & 1.46 \\
\hline nobegun & -27.716 & -2.59 & & & & \\
\hline named & $\odot .5147$ & 2.64 & 1.3052 & 4.95 & 1.6860 & 6.20 \\
\hline InArea & & & & & 2.4872 & 10.77 \\
\hline units & & & & & -0.0043 & -5.98 \\
\hline units-squared & & & & & $\odot .000 \odot$ & 5.42 \\
\hline rooms & & & & & -0.0870 & -1.22 \\
\hline Bedrms & & & & & -0.2273 & -1.31 \\
\hline baths & & & & & -0.9696 & -6.15 \\
\hline firepl & & & & & -0.0906 & -0.70 \\
\hline parking & & & & & -0.9710 & -6.44 \\
\hline saleyr & & & & & -0.0987 & -3.34 \\
\hline InRent & 0.9845 & 2.59 & 2.2878 & 3.83 & 2.8451 & 4.33 \\
\hline InInc & -1.4933 & -5.29 & 5.5425 & 9.76 & 5.0395 & 9.17 \\
\hline InPopDen & 1.2062 & 15.34 & 1.6919 & 11.36 & 1.7423 & 10.33 \\
\hline dlnRent & 1.1052 & 3.44 & 1.1463 & 1.85 & $\odot .8000$ & 1.21 \\
\hline dlnInc & -0.7078 & -2.66 & -7.5869 & -12.07 & -7.2306 & -11.75 \\
\hline dInPopDen & -1.3984 & -8.89 & 3.5759 & 7.41 & 3.3327 & 7.31 \\
\hline perwhite & 2.4662 & 7.01 & 6.3154 & 9.82 & 6.3310 & 9.74 \\
\hline perCol9 & -13.306 & -16.77 & -17.758 & -8.70 & -17.468 & -8.34 \\
\hline perPoor & 3.5621 & 3.99 & 31.347 & 16.77 & 30.984 & 16.75 \\
\hline perDrop & -12.946 & -17.88 & -11.417 & -7.89 & -10.980 & -7.65 \\
\hline dperwhite & 0.4967 & 1.25 & 1.7794 & 4.04 & 1.7312 & 3.42 \\
\hline dpercol9 & 10.631 & 11.86 & 19.499 & 7.51 & 18.912 & 7.15 \\
\hline dperPoor & -4.4433 & -5.85 & -26.342 & -15.56 & -25.167 & -15.00 \\
\hline dperDrop & 3.5653 & 5.06 & 11.534 & 5.39 & 10.465 & 5.25 \\
\hline MedYear & -0.0652 & -9.64 & -0.0913 & -17.78 & -0.0816 & -12.53 \\
\hline PeroldLost & -0.3281 & -3.83 & 0.0002 & 0.00 & -0.1111 & -1.01 \\
\hline Count Lmk & -1.2922 & -10.35 & -0.3154 & -2.95 & -0.1166 & -0.95 \\
\hline CountCHRS & 0.0630 & 29.26 & 0.0735 & 20.84 & 0.0760 & 20.53 \\
\hline Constant & 156.75 & 2.28 & 514.15 & 5.09 & 765.13 & 6.34 \\
\hline PseudoR-sq & 0.6 & & 0.6 & & 0.6 & \\
\hline observations & $13, \varepsilon$ & & 61, & & 59, & \\
\hline Log Likelihood & $-1,359$ & 1706 & $-1,34$ & 757 & $-1,21$ & 1777 \\
\hline
\end{tabular}

